\title{
FOLLOWING THE TRACES OF NAXIAN EMERY - AN IMPLEMENTATION OF ENVIRONMENTAL EDUCATION IN GEODIDACTICS
}

\author{
Kritikou S. ${ }^{1}$ and Malegiannaki $\mathbf{I}^{2}$ \\ ${ }^{1}$ Secondary Education of Cyclades, 2nd High School of Naxos, 84300 Naxos - Greece, aperathu@otenet.gr \\ ${ }^{2}$ Secondary Education of Cyclades, 2nd High School of Naxos, 84300 Naxos - Greece, \\ emalegia@phs.uoa.com
}

\begin{abstract}
During the school year 2007-08 the environmental team of Naxos 2nd Junior High school accomplished the project entitled "Following the traces of naxian emery". The emery related topic was chosen due to the great importance of this mineral to the island's life and geoenvironment. The main purpose of this project was to inform the students and also a broader public, outside Naxos, about emery - a material that played, since antiquity, a significant role in naxian society and culture, and Greek history in general. The project also intended to sensitize the students and the local community relatively to the sustainable development of regions that suffer of population and cultural decline. In a framework of research and artistic creation, the team created educational material concerning the emery issue, which is available to other schools - "The emery educational kit". This consisted of a) an information booklet concerning the stone, $b$ ) a puzzle game relative to emery mining, $c$ ) an educational board game about emery and d) a documentary film produced by the team and entitled "Following the traces of naxian emery".
\end{abstract}

Key words: naxian emery, emery educational kit, constructivist learning theory, situated learning, sustainable development, Mining Park, Naxos, Cyclades.

\section{Introduction}

Decisive factor for the development of Cyclades islands, since antiquity were their mineral resources (marble from Paros, emery from Naxos, silver from Sifnos, pumice and obsidian from Milos): (Agriantoni, 1998; Kotsakis, 2003). Emery, "Smyrigli" as Naxians call it, is known since the antiquity as "Naxian stone". It is located underneath the mountains of Naxos in lenticular formation. According to the most dominant theory, emery developed through the process of metamorphism of bauxites (Urai and Feenstra, 2001; Feenstra and Wunder, 2002). This metamorphism is calculated to have taken place during the Alpine deformation (75.000.000-25.000.000 years ago) under special conditions of pressure and temperature. It contains a large mineral variety. Corundum $\left(\mathrm{Al}_{2} \mathrm{O}_{3}\right)$ is the principal component varying from $55-65 \%$, in the first quality, to $50-55 \%$, in the second quality, and finally $<45 \%$ for the third quality. It also contains hematite $\left(\mathrm{Fe}_{2} \mathrm{O}_{3}\right)$ and magnetite $\left(\mathrm{Fe}_{3} \mathrm{O}_{4}\right)$. Some other materials that may be found as accessory phases include: micas, tourmaline $(\mathrm{Na}, \mathrm{Ca})(\mathrm{Li}, \mathrm{Mg}, \mathrm{Al})(\mathrm{Al}, \mathrm{Fe}, \mathrm{Mn})_{6}\left(\mathrm{BO}_{3}\right)_{3}\left(\mathrm{Si}_{6} \mathrm{O}_{18}\right)(\mathrm{OH})_{4}$, kynite $\left(\mathrm{Al}_{2} \mathrm{SiO}_{5}\right)$, diaspore $(\mathrm{AlO}(\mathrm{OH}))$, rutile $\left(\mathrm{TiO}_{2}\right)$, staurolite $\left(\mathrm{FeAl}_{4} \mathrm{Si}_{2} \mathrm{O}_{10}(\mathrm{OH})_{2}\right)$, vesuvianite $\mathrm{Ca}_{10}(\mathrm{Mg}, \mathrm{Fe})_{2} \mathrm{Al}_{4}\left(\mathrm{SiO}_{4}\right)_{5}\left(\mathrm{Si}_{2} \mathrm{O}_{7}\right)_{2}(\mathrm{OH})_{4}$, 


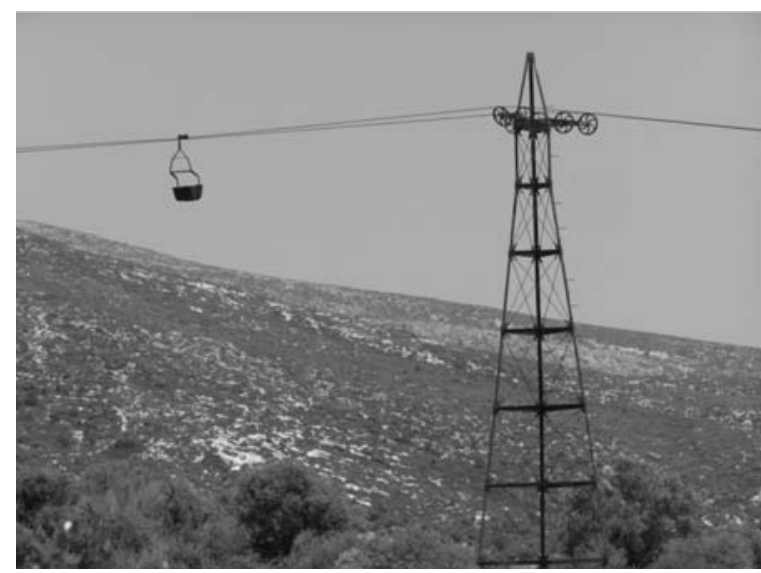

Fig. 1: A pylon and a bucket of "Enaerios", the aerial system of emery transportation.

pyrite, sillimanite $\left(\mathrm{Al}_{2} \mathrm{SiO}_{5}\right)$, chlorite $\left(\mathrm{Mg}_{6} \mathrm{Si}_{4} \mathrm{O}_{10}(\mathrm{OH})_{8}\right)$, feldspars, apatite $\mathrm{Ca}_{5}\left(\mathrm{PO}_{4}\right)_{3}(\mathrm{OH}, \mathrm{F}, \mathrm{Cl})$, garnets (Nikolaou, 2005; Christofidis and Soldatos, 2009).

Corundum is what makes emery a precious product. It is the reason why emery is noted for its great hardness and its abrading attributes. Specific weight of emery is around 4 and its hardness is between 7 and 9 on MOHS scale, depending on the quality (Nikolaou, 2005). Emery is mainly used for the smoothing of several surfaces, such as metal, glass, wood, minerals, in sand blast and as an anti-slipping material for the construction of roads.

Naxos, Samos, Heraklia, Sikinos, Paros and Ikaria are the Greek islands where emery is found. The best quality is in Naxos where the mining takes place. American and Turkish emery are also known but they are of poorer quality.

Naxian emery was one of the more significant Greek minerals for a great period of time. Naxos has long been the main emery production centre of Europe. The existence of the precious rock was located in Naxos during Ancient times. Then it was used for the creation of artefacts such as the famous Cycladic statuettes. (Kotsakis, 2003). Emery is found mostly on the mountain Ammomaxi, in northeastern Naxos, between the gulfs of Moutsouna and Lyona, near the villages Apeiranthos and Koronos. It is a region with great hypsometric differences and intense dismemberment. Geologists calculated emery reserves in that area to approximately 2.200.000 tons. The mining right, since the Turkish domination, was a privilege of the inhabitants of 6 villages: Apeiranthos, Koronos, Danakos, Mesi, Skado and Keramoti.

Emery has been a very important factor of Naxos' prosperity mainly for the first half of the 20th century, resulting to being one of the main factors of formation of the environment as well as the society of mountainous Naxos. (Archontakis and Giannoulis, 2001). Primarily emery, after being extracted, was transported to Moutsouna bay by donkeys. "Enaerios" was constructed during the years 1926-1929. "Enaerios" is an aerial system of transportation using wire ropes and buckets (Polyzos, 1997). It began functioning in 1929 and it consisted of 72 pylons, wagons, buckets, loading installations, engine rooms and depositories (Balodimou, 2003). This aerial system of transportation is one of the few that still exist in Greece (Fig. 1). It functioned until 1978. Since then, emery has been transported with trucks, through the road that connects the mines with the port of Moutsouna (Fig. 2), as the aerial transportation to the port, was thought to be uneconomical (Frangiskos, 2003).

From the post-war years and on, a declination in the emery mining has occurred. In the 90's, the natural emery was pushed aside commercially, because of the production of artificial corundum, and the 


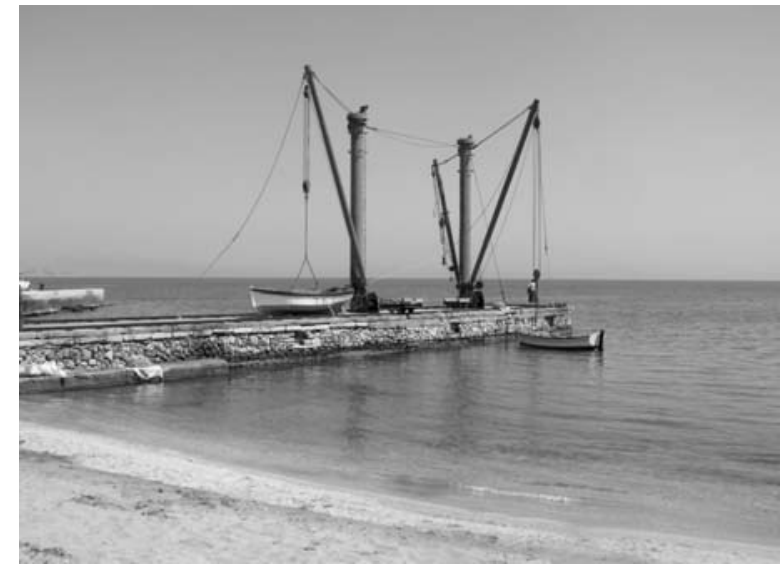

Fig. 2: The port of Moutsouna, where once emery was loaded into the barges.

expansion of cheaper but inferior qualitatively Turkish emery, but also because of the indifference of the Greek state to promote the product in the market. (Zagouras and Ioannidis, 1988).

The emery mines of Naxos, the remains of mining machinery and transportation installations, as well as the piled up quantities of the mineral, feature now to be a commemoration of the pre-industrial period and have been declared preservable by the Ministry of Culture (Gontinou and Loukma, 2006).

Despite the efforts for the solution of the emery problem, the appreciable initiatives of various institutions were not materialized (Louvi, 1996). This also was the case with the more recent study of 1986, which suggested the exploitation of emery and emery areas, through the development of a museum organized by a co-operative institution (Polyzos et al., 1996).

\section{Pedagogical framework}

\subsection{Cross thematic/ interdisciplinary character of the project}

The project "Following the traces of Naxian emery", due to its multifarious character, has dictated the use of a cross thematic and interdisciplinary approach, that indicates the close relationship of geodidactics with the didactics of other disciplines.

The starting point of the project was geology and the mineral emery. In order to define the position, creation and properties of this mineral, knowledge that served as a basis for the project, the parallel contribution of geology, geography and chemistry was needed. For the understanding of the uses of the product and the reasons of its fame, we investigated elements of modern technology but also looked back in antiquity, with the aid of archaeology, which has revealed the commercial character of emery since Neolithic era and its use in powerful tools suitable for the smoothing of marble and therefore for the creation of the famous Cycladic statuettes. Industrial archaeology had also an important role in the project, since the team examined the industrial remnants related to emery mining and transportation, in a perspective of presenting them as monuments in a future mining park.

Seeking to comprehend the rights of the Naxian highlanders in mining and sale of emery through time, the group had to consult history. The exploitation of the mineral by the Frank feudal lords changed only in the late $18^{\text {th }}$ century and the exclusive right in emery mining of six mountainous Naxian villages, still in effect, goes back to that time. Emery is also very closely related to economic history and history of trade unions. While working on the project, the students realised the impor- 
tance of emery in Greek economy, especially during the $19^{\text {th }}$ and $20^{\text {th }}$ century, and learnt about the first trade union of emery and the first strike of the emery miners in the early $20^{\text {th }}$ century.

Finally, a big part of the group's research on the spot had an anthropologic- ethnographic character, since the students examined material culture, poetry and songs, customs and traditions, proverbs and myths, social life in general in the mountainous emery villages of Naxos.

\subsection{Learning theories}

The project "Following the traces of naxian emery" is based on constructivist learning theory and situated learning.

The constructivist learning theory, in accordance to the cognitive approach to knowledge, that contradicts behaviourism, emphasizes the perspective of the learner. Knowledge does not exist as an external and absolute event, but as a product of interaction between the subject matter and the learner. The constructivist learning theory has two basic points: 1) the starting point of learning is the learner's preexisting knowledge, attitude and interests on the topic, 2) learning arises by the interaction of the above with experience (Howe and Berv, 2000). The person that is in a process of learning chooses and transforms the information, forms hypotheses based on a mental structure (schemas, mental models) that gives meaning, organizes his experience and allows him to go on further than the given information.

The implementation of constructivist learning theory in education suggests the designing of educational content that can interact with pre-existing knowledge, attitudes and interests of the individuals and can help them create their own meaning. Subsequently, special attention is needed when it comes to studying learners' needs and background. In the framework of constructivism it is generally accepted that the individual is not learning through passive acceptance of learning material. On the contrary, an active participation of the student in the procedure of knowledge construction is encouraged, using as basic tools conversation, social interaction, cooperation and negotiation (Phillips, 2000; Vosniadou, 2002; Anderson et al., 2003; Terwel, 1999). Of course, the above does not imply the exclusion of the benefits of knowledge centered environments, since the well organized and deep knowledge of a material is a prerequisite for designing a correct learner centered environment. An approach for creating curricula that encourage meaningful learning is "progressive formalization" which begins with the informal ideas that each student brings into a learning environment, and help them gradually transform and formalize them (Bransford et al., 1999).

Theory of situated learning regards learning as a multifactorial procedure that is not limited to the individual itself but is determined by a number of socio-cultural parameters (Brill, 2000). In the light of this theory, the activity through which knowledge is developed is not separated by knowledge itself. In other words situations co-produce knowledge through action.

In an effort to trace down the basic features of situated teaching, we can mention the following (Greeno et al., 1996):

- Thinking and problem solving is achieved in a frame of goals that are set by a broader social group.

- Knowledge is inseparably connected to actions.

- The use of multiple cognitive methods (mnemonic and visual aids) is enhanced.

- Cooperation with other members of the group and task distribution is expected.

- Learning takes place through tasks of various grades of complexity, similarly to what happens in real world.

- Learning tasks constitute a part of a completed project, which exists as a final goal.

- The problems do not dictate the way of solving them, but the learner must detect the possi- 
ble solutions, as it happens in daily life.

Since theory of situated learning views learning through the practices of a community and the abilities of individuals to participate in them, in teaching level it sets as a goal the encouragement of participation and the creation of an environment in which the learner can apply his/her own new knowledge. This approach turns over the discrimination between "know what" and "know how" and aims to the connection of theory with its application in practical level.

Lave and Wenger (Lave and Wenger, 1991) speak about apprenticeship and underline the importance of authentic participation of an individual in the group's activities and setting of goals. They also consider as learning motivation the individual's desire to be an active member of a community that sets learning as a value. In other words, theory of situated learning considers innate the desire of an individual to define him/herself as part of a community.

\section{Description of the program}

\subsection{Goals}

Realizing the great importance of the mineral emery to the island's life and geoenvironment, the environmental team of Naxos 2nd Junior High school chose to accomplish the project entitled "Following the traces of naxian emery". We thought that through this project the students and the teachers involved would get the chance to better familiarize themselves with the mineral that determined the history and the environment of their island. For this project, students of all grades worked together with the teachers Sofia Kritikou and Irini Malegiannaki.

The project intended to sensitize the students and the local community relatively to the sustainable development of regions that suffer of population and cultural decline. The goals of the team were:

- To learn about emery and mountainous Naxos in a pleasant and amusing way.

- To learn how to cooperate as a team.

- To create educational material concerning the emery issue, available to other schools- "The emery educational kit".

- To propose solutions for the sustainable development of the emery mining regions of Naxos island.

- To inform a broader public, outside Naxos, about a material that played a significant role in Greek history.

\subsection{Research on the spot}

The realization of the project "Following the traces of Naxian emery" was based to a large extent on excursions and research on the spot. The innate curiosity of the children has firstly led the team to the mountainous emery villages Apeiranthos and Koronos. There, the students interviewed ex emery miners, they visited the geological museum in Apeiranthos, the remnants of the aerial railway and a basic mining gallery. Inside another gallery, some of the students took part in a short mining procedure (Fig. 3 ), while later the students went downhill to the port of Moutsouna, where the mineral was loaded. The kids, disappointed of the nowadays depopulation of the Naxos highland, sought for solutions of sustainable development. They traveled to Athens, where a specialized geologist from the Museum of Mineralogy and Petrology of the University of Athens initiated them to concepts like geo-conservation and geo-tourism. Afterwards, the team traveled to Fokis. There, in the mining park Vagonetto, in Amfissa, they got acquainted with the idea of transforming a deserted mining gallery into a museum. In their way back, the children carried ideas and hopes for the creation of a cultural mining park in Naxos. 


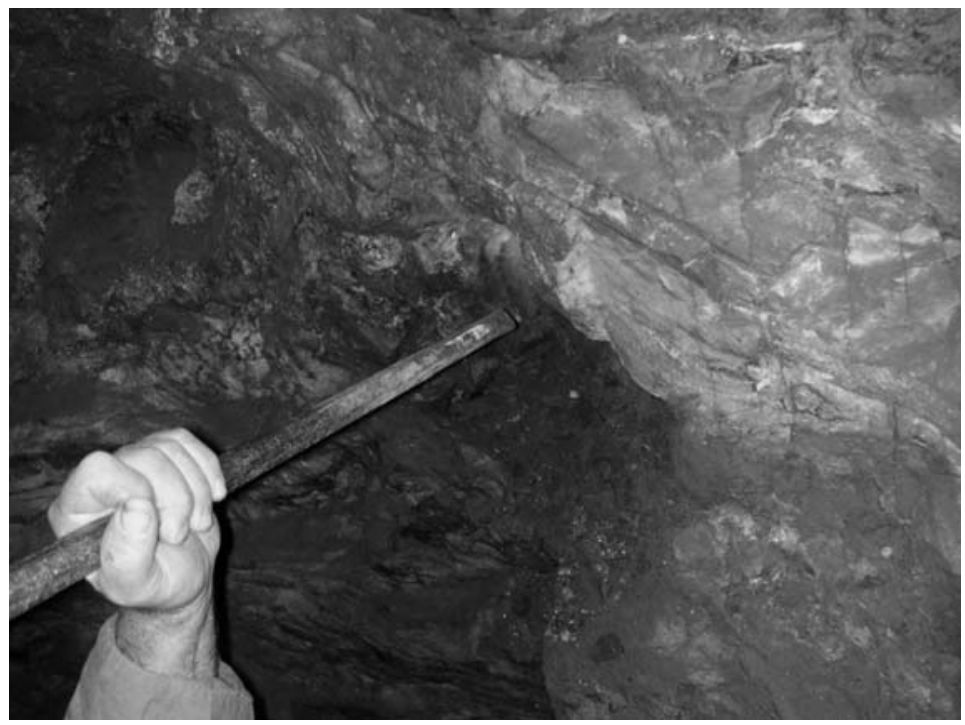

Fig. 3: Participation in a short mining procedure in a gallery near Apeiranthos.

\subsection{Contents of the "emery educational kit"}

The "emery educational kit" includes:

- An information booklet concerning the mineral emery.

- A puzzle game relative to emery mining.

- An educational board game about emery.

- A documentary film produced by the team, entitled "Following the traces of naxian Emery".

\subsubsection{The information booklet}

The method used for the creation of the emery information booklet was the division of a goal in sub goals. In order to enhance all students' involvement in the investigation of the topic, this was divided up in smaller units given in a query form. The task of each student was to gather information about each question. The unification of the material gathered created the booklet.

\subsubsection{The educational game of emery}

Keeping in mind that learning through entertainment is more effective (Kousouris and Papadogiannaki, 2005), the team constructed the emery board game (Fig. 4). The game consists of two main panels, one representing the Naxos Island and the other the emery mining regions. The players take the role of emery miners trying to arrive to the Moutsouna port in order to weigh amounts of the mineral. A correct answer to a question relative to emery or a correct dramatization of an act relative to emery mining allows them to proceed closer to their destination. However, many other activities prevent them from accomplishing their goal, for example, a holiday, a gardening task, an illness etc. The winner of the game is the player that arrives first at the port having gathered the greatest amount of emery. With this game the players, besides learning about the emery mining, get acquainted with elements of the tradition and the culture of mountainous Naxos (local dialect, proverbs, feasts, customs, material culture, social relationships). 


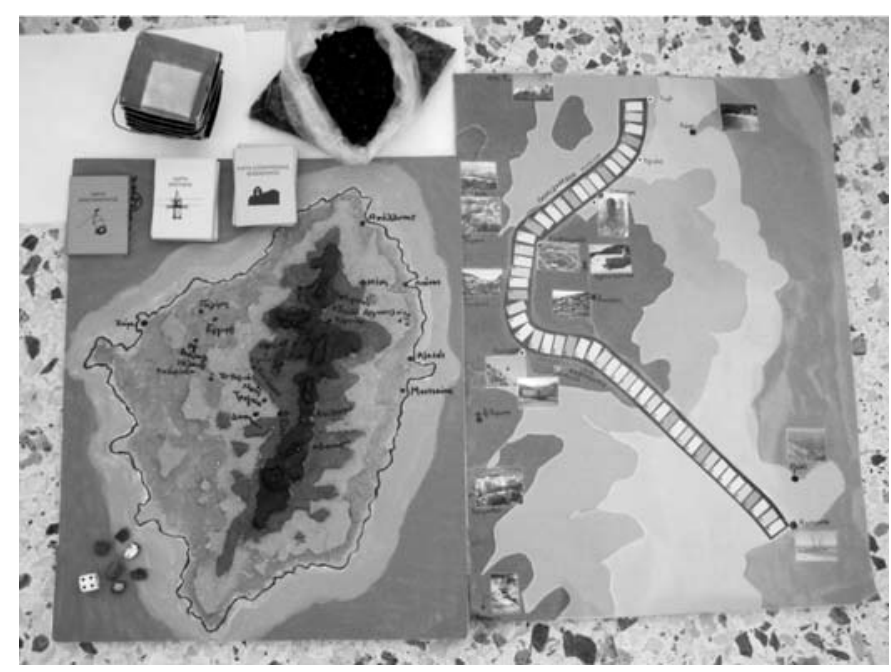

Fig. 4: The emery board game.

\subsubsection{The documentary film}

Our young cameramen recorded all their excursions with their cameras (Fig. 5). Thanks to the professional director Vaggelis Katsigiannis, the gathered material was brought together into a 35 minute documentary film entitled "Following the traces of naxian Emery". The film describes the children's experiences and at the same time gives a lot of information about emery and its mining and transportation process. It also describes the role the mineral played in the formation of the societies of the villages involved in emery mining. By watching this film the viewer gets the chance to follow the progress of the school project and at the same time learn about emery. As far as the impact of the film shooting process to the team's motivation is concerned, we can point out the following:

- The goal of a film production gave the team strong stimulus and integrated all their actions in a framework of problem solving and artistic creation.

- The use of camera added great charm to the team's campaign. The children did not just simply take a school trip, but undertook the role of a researcher, a cameraman, a designer of a completed scientific and artistic film. During the realization of the documentary, they had the chance to learn all about the phases involving film producing, camera handling, and dramatization. The collaboration with a professional director gave precious knowledge to the children and the professors, and allowed us to seek an even better result.

-We believe that the shooting of a documentary really helped in the achievement of learning via experience (Learning by doing).

\subsubsection{Presentation of the project}

As the project of the 2nd High School of Naxos came to an end, the idea of creating a cultural mining park has emerged as a possible solution to the declining and abandonment of the emery villages. All the conclusions and the material produced during the project, including "the emery educational kit" were presented to the public, in a special presentation that was organized in the town hall of Naxos. In the same location, the team also organized a digital photography display concerning the topic. 


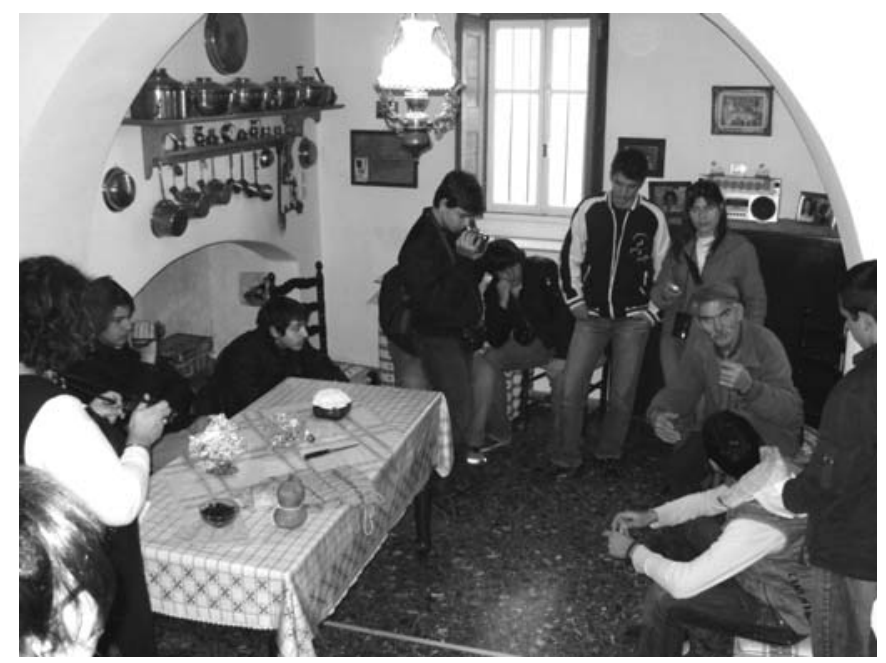

Fig. 5: Shootings during an interview with ex emery miners, in a traditional house of Apeiranthos.

\section{Conclusions}

The project "Following the traces of Naxian emery" constitutes an example of application of geodidactics - through a cross thematic framework - in environmental education. Having a mineral as starting point, a school team became engaged in the creation of a complete research and artistic work, addressed not only to the members of the team, but also to the local society and a broader public. The latter worked as a strong learning stimulus for the kids but also for the teachers-coordinators. The students, agents of different interests, abilities and preexisting knowledge, contributed each one in a particular way, to the goal setting and implementation of the project. This way, they escaped the passive approach to learning, largely imposed by the school class and became active creators of a more meaningful learning. Additionally, the framework of a team enhanced learning through social interaction, which allows the individual to achieve accomplishments that exceed its personal abilities, according to Vygotsky's (1978) "zone of proximal development". We believe that the project "Following the traces of Naxian emery" constitutes an eloquent example of creative and amusing learning that has left students and teachers a notable remembrance of the school year 2007-8.

\section{Acknowledgments}

We would like to thank Iakovos Giakoumis and Sevasti Giakoumi, Manolis Krimitzas, Manolis Kritikos, Manolis Manolas, Antonis Protonotarios, Apostolos Psarros and Manolis Kontopoulos for the valuable experience they shared with us. We also thank the Geological museum of Apeiranthos, the community of Apeiranthos, the community of Koronos and the president Mrs Axaopoulou, the Museum of Mineralogy and Petrology of the University of Athens, the Mining Park Vagonetto for their hospitality and the detailed information they have given us. Vaggelis Katsigiannis and Marilena Maurogeni are thanked for the editing of the documentary film. Finally, we thank Sofia Oikonomou, Diana Mouressan and Dimitra Papageorgiou for their precious support during the working on the project.

\section{References}

Agriantoni, Ch., 1998. Prosengiseis sto viomichaniko topio ton Kykladon. In L. Mendoni and N. Margaris, Kyklades, Istoria tou topiou kai topikes istories, Athens, YPECHODE - YPEPTH - EIE/KERA, 394-421. 
Anderson, D., Lucas, K. B., and Ginns, I. S., 2003. Theoretical Perspectives on Learning in an Informal Setting, Journal of research in science teaching, 40(2), 177-199.

Archontakis, M. and Giannoulis, G., 2001. Poiisi charagmeni stin petra, Athens, Atrapos, 77-78.

Balodimou, M., 2003. Metalleutikes skales fortosis sto Aigaio, Proceedings of Scientific Congress Historical Mines in Aegean 19 $9^{\text {th }}-20^{\text {th }}$ century, Milos, 3-5 October, PIOP, 183.

Bransford, J.D., Brown, A.L., and Cocking, R.R. (eds.), 1999. How people learn: brain, mind, experience and school, Washington D.C., National Academy Press, 124-7.

Brill, J. M., 2000. Situated cognition. In M. Orey (Eds), Emerging perspectives on learning, teaching and technology, available online at: http://projects.coe.uga.edu/epltt/index.php?title=Situated_Cognition.

Christofidis, Ch., and Soldatos, T., 2009. Minerology, Thessaloniki, Laboratory of Mineralogy, Petrology, Ore Deposits Department of Geology, available online at: http://www.geo.auth.gr/106/index.htm.

Feenstra, A., Wunder, B. 2002. Dehydration of diasporite to corundite in nature and experiment. Geology $30,119-122$.

Frangiskos, A., 2003. The alluvial transport of minerals in the islands of Aegean Sea during postwar era, Proceedings of Scientific Congress Historical Mines in Aegean 19 $19^{\text {th }}-20^{\text {th }}$ century, Milos, 3-5 October, PIOP, 193.

Gontinou, A. and Loukma, M., 2006. Poreia sti Naxo... Topoi tis Smyridas, Athens, N.T.U.A., 1-3.

Greeno, J., Collins, A., and Resnik, L., 1996. Cognition and learning. In D.C. Berliner and R.C. Calfee (eds.), Handbook of educational psychology, N.Y., APA, 26.

Howe, R. K., and Berv, J., 2000. Constructing constructivism, epistemological and pedagogical. In D.C. Phillips, Constructivism in education: opinions and second opinions on controversial issues, Chicago, D.C. Phillips (Eds.), 19-40.

Kotsakis, Th., 2003. I naxiaki smyrida kai i ekmetalleusis tis, syntomi istoriki anadromi, Proceedings of Scientific Congress Historical Mines in Aegean 19 ${ }^{\text {th }}-20^{\text {th }}$ century, Milos, 3-5 October, PIOP, 77- 81.

Kousouris, S. and Papadogiannaki, K., 2005. Perivallontika paichnidia, Athens, Dardanos.

Lave, J., and Wenger, E., 1991. Situated learning, legitimate peripheral participation, Cambridge, UK, Cambridge University Press.

Louvi, A., 1996. Proposals for museums for the conservation of mines in Aegaio. Proceedings of Scientific Congress Historical Mines in Aegean $19^{\text {th }}-20^{\text {th }}$ century, Milos, 3-5 October, PIOP, 303-305.

Nikolaou, M., 2005. Minerals - Sediments and Civilization, Museum of Natural History, Kifisia, 185.

Phillips, D.C. (2000). An opinionated account of the constructivist landscape. In D.C. Phillips, Constructivism in education: opinions and second opinions on controversial issues, Chicago, D.C. Phillips (Eds.), 1- 16.

Polyzos, G, 1997. O enaerios sta smyridorycheia Naxou, Athens, N.T.U.A. available online at: http://courses.arch.ntua.gr/111924.html

Polyzos, G., Frangiskos, A., Belavila, N., Katerini, T. and Plyta, A., 1996. Katagrafi kai apotimisi tou istorikou viomichanikou exoplismou sta smyridorycheia tis Naxou, Athens, N.T.U.A.

Terwel, J., 1999. Constructivism and its implications for curriculum theory and practice, Journal of curriculum studies, 31(2), 195-199.

Urai, J.L., Feenstra, A. 2001. Weakening associated with the diaspore-corundum dehydration reaction in metabauxites: An example from Naxos (Greece). Journal of Structural Geology 23, 941-950.

Vosniadou, St., 2002. Pos mathainoun oi mathites, Athens, Dardanos.

Vygotsky, L., 1978. Nous stin koinonia, Athens, Gutenberg, (transl. St. Vosniadou) 1997, 144 pp.

Zagouras, N. and Ioannidis, Ch., 1988. Aftonomes omades ergasias kai eksygchronismos sta smyridorycheia Naxou, Aperathitika, 1, 139. 
